\title{
Mechanism of cAMP Regulation of Renin Gene Transcription by Proximal Promoter
}

\author{
Kouichi Tamura, * Satoshi Umemura, " Satoshi Yamaguchi, * Tamio Iwamoto, * Shun-ichi Kobayashi, * Akiyoshi Fukamizu, ${ }^{\circ}$ \\ Kazuo Murakami, ${ }^{*}$ and Masao Ishii * \\ * Second Department of Internal Medicine, Yokohama City University School of Medicine, Yokohama 236; and ${ }^{\ddagger}$ Institute of Applied \\ Biochemistry, University of Tsukuba, Ibaraki 305, Japan
}

\begin{abstract}
Renin is produced mainly by the kidney, and cAMP is a main positive regulator of its synthesis. This study was undertaken to analyze the molecular mechanism of cAMPmediated regulation of Ren-1C gene transcription by the proximal promoter. We first showed that the promoter region from -365 to +16 of the mouse renin gene (Ren-1C) mediated the cAMP-induced chloramphenicol acetyltransferase gene expression in embryonic kidney-derived 293 cells. Deletion analysis and heterologous promoter assay disclosed that the proximal promoter region from -75 to +16 was able to activate chloramphenicol acetyltransferase expression by cAMP, and indicated that the proximal promoter element from -75 to -47 (RP-2 element) overlapping the TATA-like region was able to confer cAMP responsiveness. Electrophoretic mobility shift assay and DNase I footprinting analysis demonstrated that novel nuclear factors in 293 cells interacted with the RP-2 element, and that cAMP increased the binding activity of these nuclear factors to the RP-2 element. Furthermore, we demonstrated that cAMP enhanced the binding of nuclear factors derived from juxtaglomerular cells, the main production site of renin in the kidney, to the RP-2 element in vivo. These results suggest that the RP-2 element plays an important role in the cAMPmediated regulation of Ren-1C gene transcription through the proximal promoter. (J. Clin. Invest. 1994. 94:19591967.) Key words: renin • cAMP • transcriptional activation - proximal promoter $\cdot$ nuclear factor
\end{abstract}

\section{Introduction}

Renin, an aspartyl protease, has an important role in the regulation of blood pressure and water-electrolyte balance by catalyzing the rate-limiting step of the renin-angiotensin system (1, 2 ), and it may be involved in the pathogenesis of hypertension (3-6). The expression of the renin gene is regulated in a tissuespecific manner, and the main production site of circulating renin is the kidney. In the kidney, the principal cells of origin

\footnotetext{
Address correspondence to Satoshi Umemura, M.D., Second Department of Medicine, Yokohama City University School of Medicine, 39, Fukuura, Kanazawa-Ku, Yokohama 236, Japan.

Received for publication 22 March 1994 and in revised form 21 June 1994.
}

J. Clin. Invest.

(C) The American Society for Clinical Investigation, Inc. 0021-9738/94/11/1959/09 \$2.00

Volume 94, November 1994, 1959-1967 for circulating renin are the juxtaglomerular (JG) ${ }^{1}$ cells, which synthesize, store, and release renin $(1,2)$. Our transgenic studies previously demonstrated that the $5^{\prime}$-flanking region of the human renin gene directed tissue-specific expression in the JG cells of the kidney $(7,8)$. In addition, we identified two transcriptionally important promoter elements (RU-1, -224 to -138 ; and RP-2, -75 to -47 ) in the mouse renin gene (Ren$1 C)$, and demonstrated that the combination of these elements was responsible for cell type-specific transcriptional activity of the Ren-1C gene in transfected kidney cells $(9,10)$. The RP-2 element was critically important to direct cell type-specificity, and the RU-1 element synergistically supported the high level basal promoter activity directed by the RP-2 element. Furthermore, a recent study using a pituitary cell line indicated that the pituitary-specific factor bound to the proximal promoter and regulated transcription (11), and previous studies demonstrated that 5'-flanking sequences of the mouse renin gene (Ren-2) directed tissue- and development-specific expression of the reporter SV-40 T antigen gene in transgenic mice (12, 13). 5'-Flanking sequences of the mouse, rat, and human renin genes have significant homology, and it is assumed that the highly homologous promoter regions of these renin genes may be involved in the regulation of the renin genes expression in the kidney $(14,15)$.

The biosynthesis of renin in the kidney is concomitantly regulated by a variety of factors, including sodium chloride balance, blood pressure, sympathetic nerve activity, and angiotensin II $(1,2)$. The intracellular levels of cAMP, also an important mediator of renal physiological response to different stimuli (16-19), have an especially significant influence on the synthesis and secretion of renin in the kidney, as revealed by in vitro and in vivo studies $(1,2,20,21)$. Recent studies have shown that the upstream 5'-flanking region of the mouse renin genes (Ren-1D and Ren-2) could activate transcription from a heterologous promoter in transfected chorion-derived cells, and identified a cAMP-responsive element (CRE) (Ren-1D, -619 to -597 of the transcriptional start site; Ren-2, -670 to -648 ) $(22,23)$. Furthermore, a previous DNA transfection study in primary chorion cells disclosed that the first $100 \mathrm{bp}$ of the human renin promoter region could direct cAMP-induced transcription (24).

In the present study, we show that the proximal promoter region from -75 to +16 of the mouse renin gene (Ren-1C) was able to mediate the transcriptional activation by cAMP in human embryonic kidney-derived 293 cells. In addition, we

1. Abbreviations used in this paper: 8-Br-cAMP, 8-bromo-cAMP; CAT, chloramphenicol acetyltransferase; CRE, cAMP-responsive element; CREB/ATF, CRE-binding protein/activating transcription factor; EMSA, electrophoretic mobility shift assay; $\mathrm{H}-8, \mathrm{~N}$-(2-[methylamino]ethyl)-5-isoquinoline-sulfonamide; JG, juxtaglomerular; NRE, negative regulatory element; TK, thymidine kinase. 
demonstrated that the RP-2 element $(-75$ to -47$)$ in the Ren$1 \mathrm{C}$ gene promoter, which overlapped the TATA-like region, was the major contributor to the regulation of the Ren-1C promoter activity by cAMP in 293 cells. Electrophoretic mobility shift assay (EMSA) showed that nuclear factors, which were distinct from AP-1, AP-2, and CRE-binding protein/activating transcription factor (CREB/ATF) family transcription factors, interacted with the RP-2 element, although cAMP-protein kinase pathway might be involved in the cAMP-mediated activation of the Ren-1C promoter by the RP- 2 element. Furthermore, we disclosed that the nuclear factors in the JG cells, the major production site of renin in the kidney, actually bound to the RP-2 element, and demonstrated that nuclear factors binding to the RP-2 element were regulated by cAMP in vivo.

\section{Methods}

Plasmid construction, cell culture, and transient transfection assay. The renin promoter-chloramphenicol acetyltransferase (CAT) chimeric constructs, mRn365CAT, mRn224CAT, mRn183CAT, mRn164CAT, mRn114CAT, mRn75CAT, and mRn47CAT were constructed as described previously (9). For construction of an internal deletion mutant, mRn $\Delta$ 365CAT, 290-bp ( -365 to -76$) \mathrm{XbaI}-\mathrm{HaeIII}$ fragment was inserted in the sense orientation to the BglII site of mRn365CAT. The RU-1 or RP-2 elements, with or without the other element, were linked upstream to the renin minimal promoter $(-47$ to +16$)$ or to the herpes simplex virus-thymidine kinase (TK) promoter (25) in 5 ' to $3^{\prime}$ orientation. In addition, the RP-2 element or CRE of the human chorionic gonadotropin $\alpha$-subunit gene (26), with or without the other element, were linked upstream to the TK promoter in $5^{\prime}$ to $3^{\prime}$ orientation. Human embryonic kidney-derived 293 cells were maintained in MEM containing $10 \%$ horse serum as described previously (9). DNA transfection and CAT assay were performed essentially as described previously ( 9 , $10,27)$. Briefly, cultured cells were transfected with $4 \mu \mathrm{g}$ of the Ren1C promoter-CAT hybrid gene by the $\mathrm{CaPO}_{4}$ coprecipitation method. After incubation for $12 \mathrm{~h}$ at $37^{\circ} \mathrm{C}$, cells were further cultured for $36 \mathrm{~h}$ in the presence or absence of $1 \mathrm{mM}$ 8-bromo-cAMP (8-Br-cAMP) or $15 \mu \mathrm{M} \mathrm{N}$-(2-[methylamino]-ethyl)-5-isoquinoline-sulfonamide ( $\mathrm{H}-8)$ (28), and aliquots of cell extracts containing equal amounts of cell lysate protein $(40 \mu \mathrm{g})$ were used in CAT assay.

Isolation and analysis of RNA. Northern blot analysis was performed essentially as described previously (29-31). Mice were injected with 8-Br-cAMP ( $10 \mathrm{mg} / \mathrm{kg}$ body wt, i.p.) or an equal volume of vehicle 5 $\mathrm{h}$ before killing. Total RNA was isolated from kidney, spleen, liver, and enriched JG cells, using the single-step method by acid guanidinium thiocyanate-phenol-chloroform extraction (32). $10 \mu \mathrm{g}$ of each total RNA sample was denatured with $1 \mathrm{M}$ glyoxal and $50 \%$ dimethyl sulfoxide, electrophoresed on a $1.2 \%$ agarose gel, and transferred to a nylon membrane (GeneScreen Plus; Du Pont-NEN, Boston, MA). Filters were prehybridized for $30 \mathrm{~min}$ at $60^{\circ} \mathrm{C}$ in a solution consisting of $1 \%$ SDS, $1 \mathrm{M} \mathrm{NaCl}$, and $10 \%$ dextran sulfate. Hybridization proceeded for $16 \mathrm{~h}$ at $60^{\circ} \mathrm{C}$ in the same solution containing $300 \mu \mathrm{g} / \mathrm{ml}$ denatured salmon sperm DNA and $1 \times 10^{6} \mathrm{cpm} / \mathrm{ml}$ of the ${ }^{32} \mathrm{P}$-labeled mouse renin cDNA probe (33) or mouse skeletal $\beta$-actin cDNA probe (34). Filters were washed twice with $2 \times \mathrm{SSC}(1 \times \mathrm{SSC}=0.15 \mathrm{M} \mathrm{NaCl}, 0.015 \mathrm{M}$ sodium citrate) for $5 \mathrm{~min}$ at room temperature, twice with $2 \times \mathrm{SSC}$ and $1 \%$ SDS for $30 \mathrm{~min}$ at $60^{\circ} \mathrm{C}$, and twice with $0.1 \times \mathrm{SSC}$ for $30 \mathrm{~min}$ at room temperature. Dried filters were subjected to autoradiography at $-70^{\circ} \mathrm{C}$ with an intensifying screen. Expression of renin mRNA was quantitated using FUJIX BIO-Imaging Analyzer BAS2000 (Fuji Photo Film, Tokyo, Japan), and it was normalized to the signal generated by probing for a constitutive $\beta$-actin gene expression.

Preparation of nuclear extracts. Nuclear extracts from 293 cells were prepared using a modification of the protocol of Dignam et al. $(35,36)$. The final protein concentration was $5-7 \mathrm{mg} / \mathrm{ml}$. In some instances, cultured cells were exposed to $1 \mathrm{mM} \mathrm{8-Br-cAMP}$ or to 15 $\mu \mathrm{M}$ H-8 for $36 \mathrm{~h}$ before the preparation of nuclear extracts. Nuclear extracts from C57BL/6 mouse kidney, spleen, and liver were prepared essentially according to the procedure of Gorsky et al. (37). Mice were injected with 8-Br-cAMP ( $10 \mathrm{mg} / \mathrm{kg}$ body wt, i.p.) or an equal volume of vehicle $5 \mathrm{~h}$ before killing. The final protein concentrations of the nuclear extracts were in the range of 3-4 mg/ml. Preparation of nuclear extracts from enriched JG cells was performed according to the methods of Kurtz et al. (38) and of Horiuchi et al. (22). Briefly, kidney cortex was collected from 50 C57BL/ 6 mice, minced, and digested with $0.1 \%$ collagenase and $0.25 \%$ trypsin. The cell suspension was then subjected to sieving using a pore size of $0.20 \mu \mathrm{m}$. Renin activity and mRNA expression of the cell suspension after sieving were five to six and three to four times higher than those before sieving, respectively. This ratio of concentration was comparable to that reported previously (22). Nuclear extracts were prepared using a modification of the protocol of Dignam et al. $(35,36)$. The final protein concentration was $1-2 \mathrm{mg} / \mathrm{ml}$.

Electrophoretic mobility shift assay. EMSA was performed essentially as described previously $(9,30,39)$. Briefly, nuclear extracts were preincubated for $15 \mathrm{~min}$ on ice in a $20-\mu 1$ reaction mixture containing 12 mM Hepes, pH 7.9, $60 \mathrm{mM} \mathrm{KCl,} 0.1 \mathrm{mM}$ EDTA, $0.5 \mathrm{mM}$ DTT, 0.5 mM PMSF, $12 \%$ glycerol, and 500 ng of double-stranded poly (dI-dC). Nonlabeled competitor was included in some of the binding reactions as indicated. The double-stranded oligonucleotide of the RP-2 element was phosphorylated on its 5 '-ends by T4 kinase and $\left[\gamma_{-}{ }^{32} \mathrm{P}\right] \mathrm{ATP}$, and was used as the probe. $0.1-0.4 \mathrm{ng}(\sim 15,000 \mathrm{cpm})$ of the probe was added and the incubation continued for $30 \mathrm{~min}$ at room temperature. The incubation mixture was loaded on a $4 \%$ polyacrylamide gel in a buffer containing $50 \mathrm{mM}$ Tris- $\mathrm{HCl}, \mathrm{pH} 8.3,192 \mathrm{mM}$ glycine, and 1 $\mathrm{mM}$ EDTA, and electrophoresed at $140 \mathrm{~V}$ for $3 \mathrm{~h}$, followed by autoradiography. Radioactivity of shifted bands on the gel was quantitated using FUJIX BIO-Imaging Analyzer BAS2000. Double-stranded oligonucleotides containing the consensus binding sequences for AP-1 and AP-2 were obtained from Stratagene (GELSHIFT ${ }^{\mathrm{TM}}$ KIT; La Jolla, CA). Oligonucleotides of the RP-2 element and those corresponding to the CRE of human chorionic gonadotropin $\alpha$-subunit gene (26) were synthesized on an oligonucleotide synthesizer (Cyclone ${ }^{\mathrm{TM}}$ Plus; MilliGen/ Biosearch, Burlington, MA) and purified on OPC columns (Applied Biosystems Inc., Foster City, CA), as described by the manufacturer.

DNase I footprint analysis. DNase I footprinting was performed essentially as described previously (39). Briefly, the Ren-1C promoter fragment from -114 to +16 relative to the transcriptional start site was end-labeled with T4 polynucleotide kinase and $\left[\gamma-{ }^{32} \mathrm{P}\right]$ ATP, followed by digestion with DdeI $(-18)$ to generate probes suitable for DNase I footprinting. After gel purification, the probe $(\sim 15,000 \mathrm{cpm})$ was incubated with nuclear extracts in a 50- $\mu$ l reaction volume containing 12 $\mathrm{mM}$ Hepes, $\mathrm{pH} 7.9,60 \mathrm{mM} \mathrm{KCl}, 4 \mathrm{mM} \mathrm{MgCl}_{2}, 0.1 \mathrm{mM}$ EDTA, 0.5 $\mathrm{mM}$ DTT, $0.5 \mathrm{mM}$ PMSF, $10 \%$ glycerol, and $1 \mu \mathrm{g}$ of double-stranded poly (dI-dC). The mixture was incubated for $30 \mathrm{~min}$ on ice, followed by $1 \mathrm{~min}$ at room temperature by the addition of $50 \mu \mathrm{l}$ of a solution containing $12 \mathrm{mM}$ Hepes, $\mathrm{pH} 7.9,5 \mathrm{mM} \mathrm{CaCl}_{2}, 5 \mathrm{mM} \mathrm{MgCl}_{2}$, and 5$250 \mathrm{ng}$ of DNase I. The reaction was stopped by the addition of 100 $\mu 1$ of $12 \mathrm{mM}$ Hepes, $\mathrm{pH} 7.9,0.6 \mathrm{M}$ sodium acetate, $\mathrm{pH} \mathrm{7,0.5 \%} \mathrm{SDS,}$ $0.1 \mathrm{mM}$ EDTA, and $20 \mu \mathrm{g}$ of tRNA. The DNA was extracted with phenol-chloroform $(1: 1, \mathrm{vol} / \mathrm{vol})$ and precipitated with $2.5 \mathrm{vol}$ of ethanol before electrophoresis on a $6 \%$ polyacrylamide/ $8 \mathrm{M}$ urea sequencing gel. To define the position of the protected region, $G+A$ sequence ladders were prepared (40).

\section{Results}

Renin proximal promoter activation by cAMP. We previously demonstrated that human embryonic kidney-derived 293 cells directed transcription of the Ren-1C promoter (9), and that second messenger cAMP enhanced transcription in 293 cellspecific manner by CAT assay (10). To define DNA sequences responsible for transcriptional activation of the Ren-1C promoter by cAMP in 293 cells, a 381-bp XbaI-EcoT14I fragment of the gene containing the 365-bp 5'-flanking region, the transcriptional start site, and the 16-bp exon 1 at positions -365 to 
A

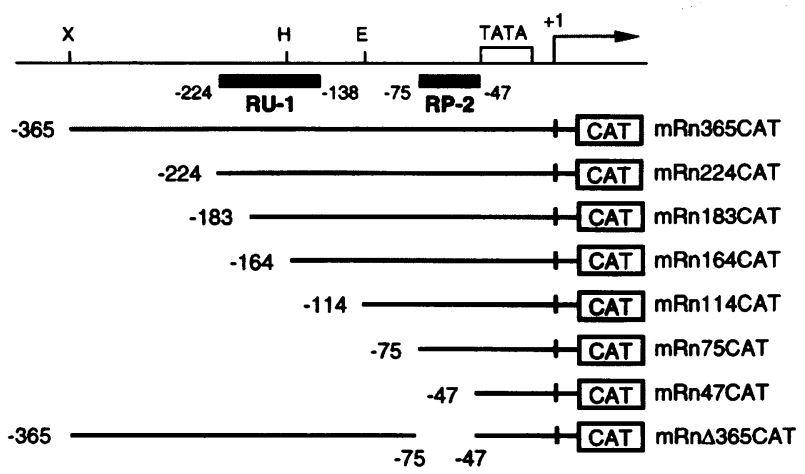

B

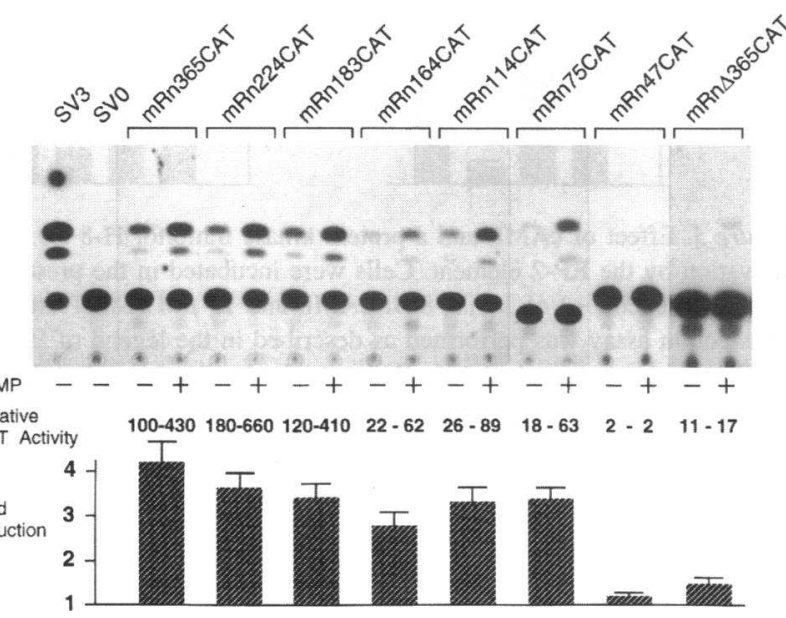

Figure 1. cAMP-induced transcriptional activation of the renin promoter. $(A)$ Schematic representation of the mouse renin promoter and construction of the renin promoter-CAT hybrid genes. Restriction endonuclease cleavage sites are indicated as follows: $X, \mathrm{XbaI} ; H$, Hinf I; $E$, EcoT14I. The TATA box is located at nucleotide positions -31 to -25 , and the transcriptional start site is indicated by +1 . RU-1 and RP-2 elements are shown by the solid boxes. $(B)$ Basal and cAMP-induced expression of the hybrid genes in transfected 293 cells. Transfection was performed using $4 \mu \mathrm{g}$ of plasmid DNA as a $\mathrm{CaPO}_{4}$ coprecipitate. Cells were incubated for $36 \mathrm{~h}$ in the presence $(+)$ or absence $(-)$ of $1 \mathrm{mM} 8$-Br-cAMP. Cells were harvested and aliquots of cell extract containing equal amounts of total protein $(40 \mu \mathrm{g})$ were used in CAT assay. SV3 and SV0 were used as positive and negative controls, respectively. Relative CAT activities were determined by averaging six independent experiments and comparing them with the basal level activity obtained from cAMP $(-)$ cells transfected with the mRn365CAT DNA. Fold induction represented the ratio of cAMP $(+) /$ cAMP $(-)$ activity for each $5^{\prime}$-deletion construct, and they were expressed as mean \pm SEM $(n=6)$.

+16 was inserted to the BglII-HindIII sites of pUCSVOCAT in the sense orientation with respect to the CAT gene (mRn365CAT), and a series of 5'-deletion mutants extending from -365 to -47 were constructed and tested for their ability to promote transcription (Fig. $1 A$ ). These chimeric constructs were introduced transiently into 293 cells, and incubated in the presence $(+)$ or absence $(-)$ of $1 \mathrm{mM} 8-\mathrm{Br}$-cAMP for $36 \mathrm{~h}$. The promoterless plasmid pUCSVOCAT was used as a background reference, and pUCSV3CAT was used as a positive control including the SV-40 enhancer-promoter region (41).

As shown in Fig. $1 \mathrm{~B}, \mathrm{mRn} 365 \mathrm{CAT}$ was able to activate CAT expression to a significant level $(4.3 \pm 0.5$-fold increase $)$ by treatment for $36 \mathrm{~h}$ with 8-Br-cAMP, and only the 91-bp Ren-1C promoter sequences $(-75$ to +16$)$ were required to elicit the CAMP-induced expression of the CAT reporter gene in 293 cells (Fig. $1 \mathrm{~B}, \mathrm{mRn} 75 \mathrm{CAT}$ ). Although the fold induction ratios of all mutants with deletion endpoints up to -75 ( $\mathrm{mRn} 75 \mathrm{CAT}$ ) were relatively constant, the relative CAT activity in both 8-Br-cAMP untreated and treated 293 cells was reduced significantly between $-183(\mathrm{mRn} 183 \mathrm{CAT})$ and -164 (mRn164CAT). Deletion of the sequences from -75 to -48 abolished the induction of CAT activity by 8-Br-cAMP ( $m R n 47 C A T)$. Furthermore, internal deletion of the sequences from -75 to -48 from the mRn365CAT construct dramatically decreased the basal and cAMP-induced CAT expression (Fig. $1 B, \mathrm{mRn} 365 \Delta \mathrm{CAT})$. These results indicated that the induction of CAT expression by cAMP was dependent on the Ren-1C proximal promoter sequences, and suggested that the RP-2 element from -75 to -47 was important for the cAMP-induced promoter activity of the Ren-1C gene.

Identification of the RP-2 element ( -75 to -47$)$ responsible for $c A M P$-induced promoter activation. To assess the functional importance of the RU-1 and RP-2 elements in the Ren-1C promoter activation by 8 -Br-cAMP, we first ligated these elements with or without the other element in $5^{\prime}$ to $3^{\prime}$ orientation into the Ren-1C promoter (Fig. $2 A$ ). A construct combining the RU-1 and RP-2 elements (mRn[RU-1/RP-2]47CAT) efficiently activated the Ren-1C promoter by $8-\mathrm{Br}$-cAMP treatment (2.9 \pm 0.4 -fold), and the RP-2 element alone (mRn[RP-2]47CAT) could also support cAMP-inducible activation of the Ren-1C promoter (3.7 \pm 0.6 -fold), although the relative CAT activity of $\mathrm{mRn}$ [RP-2]47CAT in the presence or absence of 8Br-cAMP was significantly lower relative to that of $m R n$ [RU1/RP-2]47CAT. In contrast, mRn[RU-1]47CAT, which contained the RU-1 element alone, as well as the control mRn47CAT, was not able to confer the cAMP-inducibility.

To further establish the functional role of the RU-1 and RP2 elements in directing cAMP-induced CAT expression, the RU-1 and/or RP-2 elements were linked upstream of TK promoter-CAT hybrid gene. As shown in Fig. $2 B$, [RU-1/RP2]TK-CAT was able to elicit the cAMP-induced expression of the CAT-reporter gene (2.6 \pm 0.4 -fold activation). In addition, the RP-2 element alone could mediate the transcriptional activation by 8 -Br-cAMP ([RP-2]TK-CAT, 2.7 \pm 0.4 -fold activation). In contrast, the RU-1 element alone ([RU-1]TK-CAT) could not confer the cAMP inducibility, although this element activated TK promoter in CAMP-independent manner. These results suggested that the RU-1 element functioned as a constitutive activator of TK promoter, and that the RP-2 element was necessary, not only for basal Ren-1C promoter activity, but also for cAMP-mediated activation of Ren-1C and TK promoters.

The above results suggested that the RP-2 element was responsible for the cAMP responsiveness by the proximal promoter region of the Ren-1C gene. Previous studies suggested that CRE-binding proteins activated the Ren-1D and Ren-2 genes transcription through the putative CRE in the upstream 5 '-flanking regions (Ren-1D, -619 to -597 ; and Ren-2, -670 to -648$)(22,23,42)$. To assess the functional relationship between the CRE and RP-2 element, CRE with or without the RP-2 element was linked upstream of the Ren-1C promoteror TK promoter-CAT hybrid genes. As shown in Fig. 2, $A$ and $B$, CRE alone could mediate the transcriptional activation by 8-Br-cAMP. Combination of the CRE and RP-2 element further increased the activated level of CAT expression by $8-\mathrm{Br}$-cAMP, 
A

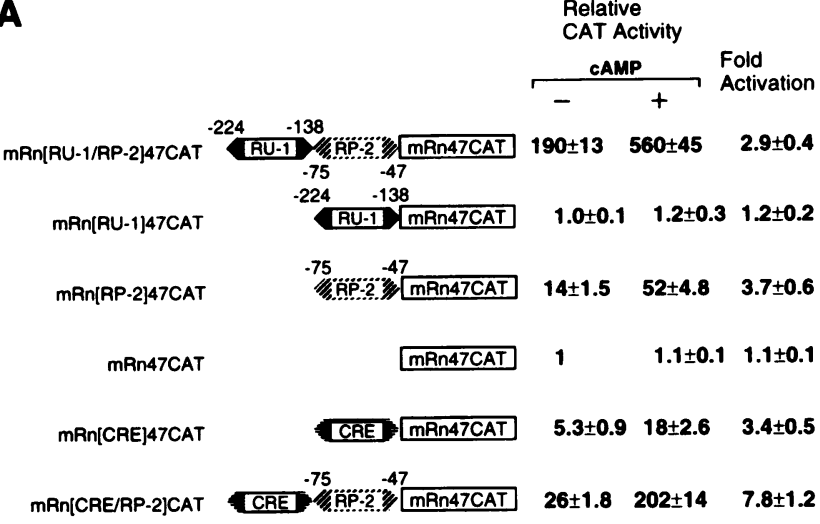

B

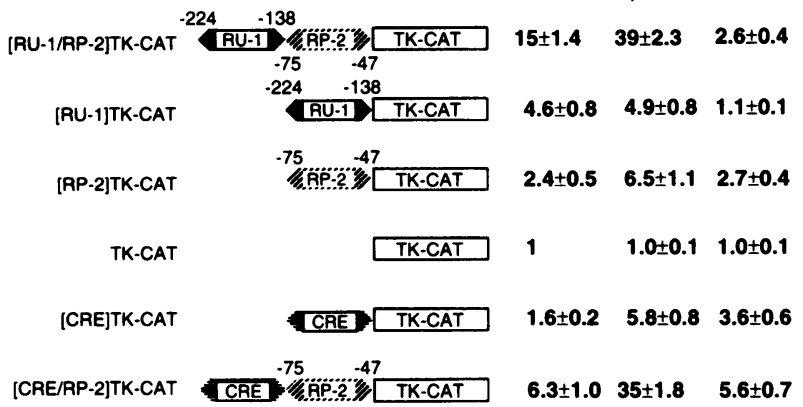

Figure 2. Effect of the RU-1 and RP-2 elements on the Ren-1C and heterologous TK promoters to direct cAMP-induced transcription. $(A)$ The RU-1 (solid box) or RP-2 (hatched box) elements, with or without the other element, were linked upstream to renin promoter (mRn47CAT) in $5^{\prime}$ to $3^{\prime}$ orientation, and transient transfection experiments were performed as described in the legend of Fig. 1. In addition, CRE was linked to mRn47CAT with or without the RP-2 element. Each construct is schematically shown on the left. CAT activities were calculated relative to the level achieved with mRn47CAT included in each experiment. Fold activation represented the ratio of cAMP $(+) /$ cAMP $(-)$ activity for each construct, and values were expressed as mean \pm SEM of five independent experiments. $(B)$ The RU-1 (solid box) or RP-2 (hatched box) elements, with or without the other element, were linked upstream to TK promoter (TK-CAT) in $5^{\prime}$ to $3^{\prime}$ orientation, and transient transfection experiments were performed as in $A$. In addition, CRE was linked to TK-CAT with or without the RP-2 element. CAT activities were calculated relative to the level achieved with TKCAT included in each experiment. Fold activation represented the ratio of cAMP (+)/cAMP (-) activity for each construct, and values were expressed as mean \pm SEM of five independent experiments.

indicating that the CRE, as well as the RP-2 element, are able to mediate the cAMP-induced activation of the Ren-1C promoter.

H-8 is an effective inhibitor of cyclic nucleotide-dependent protein kinases such as cAMP-dependent protein kinase (protein kinase A) and cGMP-dependent protein kinase (28). cAMP activates the catalytic subunit of protein kinase $\mathrm{A}$, and this subunit translocates into the nucleus, where it phosphorylates nuclear proteins such as CRE-binding proteins (43). To test whether the activation of cyclic nucleotide-dependent protein kinases was necessary for the cAMP-induced CAT gene transcription by the RP-2 element, 293 cells were treated with $1 \mathrm{mM}$ 8-Br-cAMP and/or $15 \mu \mathrm{M} \mathrm{H}-8$ for $36 \mathrm{~h}$ after the transfection of
A

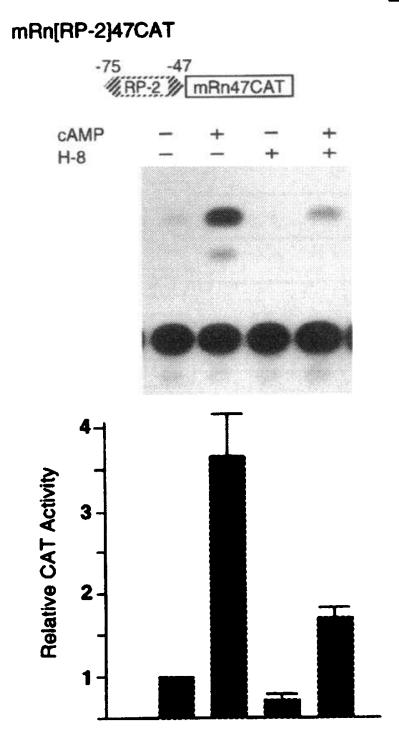

[RP-2]TK-CAT
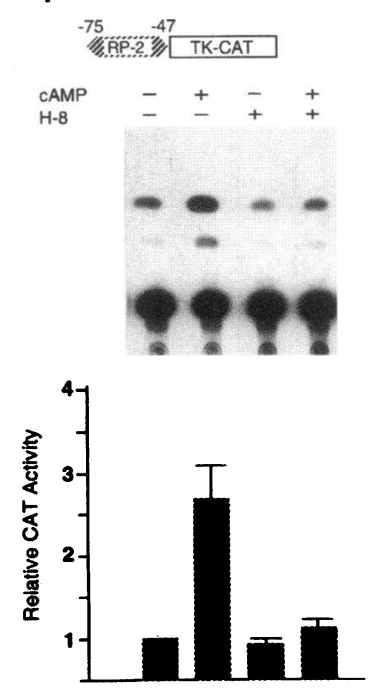

Figure 3. Effect of cAMP and a protein kinase inhibitor H-8 on CAT activation by the RP-2 element. Cells were incubated in the presence $(+)$ or absence $(-)$ of $1 \mathrm{mM}$ 8-Br-cAMP and $15 \mu \mathrm{M}$ H-8. Transient transfection assay was performed as described in the legend of Fig. 1. CAT activities were calculated relative to the level achieved with $\mathrm{mRn}$ [RP-2]47CAT or [RP-2]TK-CAT in the absence of cAMP and $\mathrm{H}-8$, and values were expressed as mean \pm SEM of four independent experiments.

mRn[RP-2] 47CAT and [RP-2]TK-CAT DNAs. As shown in Fig. 3, H-8 treatment greatly reduced the cAMP-induced activation property of the RP-2 element on Ren-1C and TK promoters.

Effect of cAMP on nuclear factors binding to the RP-2 element. We previously demonstrated that 293 cell-dominant nuclear factors bound to the RP-2 element by EMSA (9). To examine the effect of cAMP on nuclear factors binding to this element, we first performed DNase I footprint analysis. A labeled DNA fragment from -114 to -19 was incubated with 293 cell nuclear extracts followed by DNase I digestion. The results in Fig. $4 \mathrm{~A}$ showed that a sequence from -68 to -55 in the RP-2 element, overlapping the TATA-like region (TAATAAA; -67 to -61 ), was protected from digestion by DNase I (Fig. $4 A$, lanes 3 and 4, as denoted by the hatched box). The pattern of DNase I protection did not disclose any significant change upon 8-Br-cAMP treatment (Fig. $4 \mathrm{~A}$, lane 5).

Next, we carried out EMSA using the RP-2 element as the probe. As shown in Fig. 5 A, the incubation of 293 cell nuclear extracts with this element produced a single shifted band, which was competed specifically by the unlabeled RP-2 element. Double-stranded oligonucleotides containing the consensus binding sites for CREB/ATF, AP-1, or AP-2 did not efficiently compete with the RP-2 element binding activity (Fig. $5 \mathrm{~A}$, lanes 6-11). Interestingly, 8-Br-cAMP treatment had a tendency to increase the intensity of the shifted band derived from nuclear factors binding to the RP-2 element (Fig. $5 B$, lanes 1 and 2). In addition, a potent inhibitor of cyclic nucleotide-dependent protein kinases, $\mathrm{H}-8$, with or without $8-\mathrm{Br}-\mathrm{cAMP}$, inhibited this increase in binding activity to the RP- 2 element (Fig. $5 \mathrm{~B}$, lanes 3 and 4 ). The above results indicated that the binding of nuclear factors to the RP-2 element was increased by 8-Br-cAMP, although the binding region did not seem to change, and suggested 
A

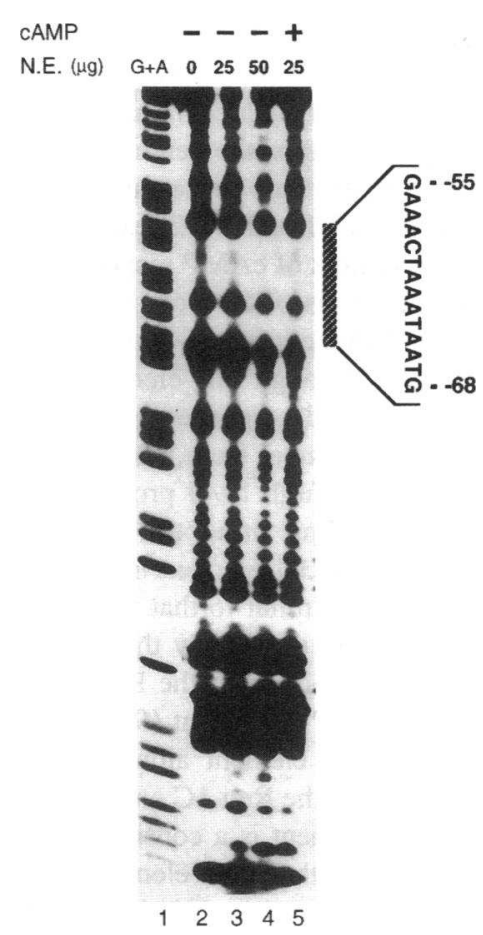

B

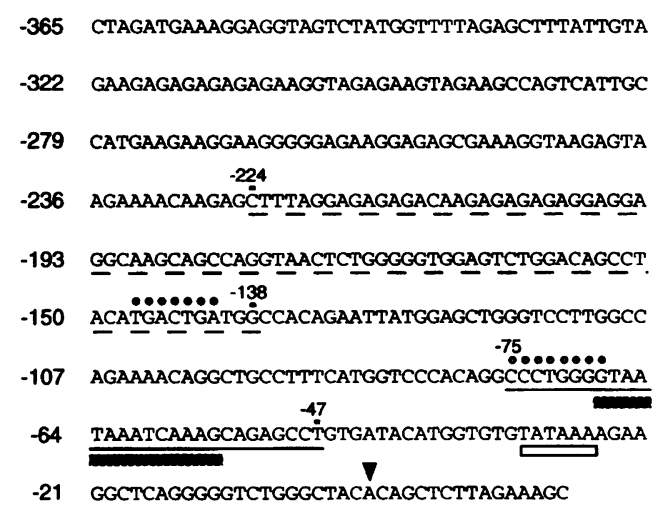

Figure 4. Analysis of nuclear factor binding to the RP-2 element by DNase I footprint analysis. ( $A$ ) DNase I footprint analysis of the RP-2 element with 293 cell nuclear extracts in the presence $(+)$ or absence $(-)$ of $1 \mathrm{mM} \mathrm{8-Br-}$ cAMP. A 130-bp EcoT14I fragment containing renin promoter sequences from positions -114 to +16 was labeled on the coding strand at the $5^{\prime}$ end. The DNA probe ( 1.5 $\times 10^{4} \mathrm{cpm}$ ) was incubated with nuclear extract derived from 293 cells incubated in the presence $(+)$ or absence $(-)$ of 8-Br-cAMP for $36 \mathrm{~h}$, and then subjected to DNase I digestion. Lane 2 contains no nuclear extract. The protected region is denoted by the hatched box to the right with its nucleotide sequences. Lane $l$, guanosine $(G)$ and adenosine $(A)$ sequencing-reaction molecular mass markers. $(B)$

Nucleotide sequence of the $5^{\prime}$-flanking region of the mouse renin (Ren-1C) gene. Nucleotides are numbered at the left with the putative initiation site of transcription denoted by the arrowhead $(+1)$. TATA box is indicated by the open box. Filled and open circles indicate consensus-like sequences for AP-1 and AP-2, respectively. RU-1 and RP-2 elements are underlined by dashed and solid lines. The protected region is denoted by the hatched box.

that the cAMP-protein kinase pathway might be involved in this increase of binding.

Effect of cAMP on renin $m R N A$ expression and nuclear factors binding to the RP-2 element in vivo. The JG cells, which are the main renin-producing cells in the kidney, constitute only a small fraction of the total cells in the kidney. To examine whether the nuclear factors binding to the RP-2 element were involved in cAMP regulation of renin mRNA expression in vivo, total RNA and nuclear extracts were isolated from the kidney and from the enriched JG cells of the kidney. Northern blot analysis was carried out using the mouse renin cDNA as the probe (33), and EMSA was performed using the RP-2 element as the probe. As shown in Fig. $6 A$, renin mRNA was expressed in the whole kidney and higher levels of mRNA were observed in the enriched JG cells. No transcript was found in the spleen and liver. 8-Br-cAMP treatment increased renin mRNA expression in the kidney and enriched JG cells. The results in Fig. $6 B$ showed that the binding of nuclear factors to the RP2 element was observed with the nuclear extracts from the kidney and enriched JG cells (Fig. $6 \mathrm{~B}$, lanes 3-6), similar to that observed with 293 cell nuclear extracts (Fig. $6 \mathrm{~B}$, lane 2). The formation of the shifted band could be inhibited efficiently with the unlabeled RP-2 element (Fig. $6 \mathrm{~B}$, lanes 7 and 8). Furthermore, the shifted bands showed increases in intensity upon 8-Br-cAMP treatment of mice, which was the same result as that with nuclear extracts from 293 cells. These shifted bands could not be competed with the oligonucleotides of the consensus motifs for CREB/ATF, AP-1, or AP-2 (data-not shown). On the other hand, incubation of spleen or liver nuclear extracts with the RP-2 element did not produce any shifted band in the presence or absence of 8-Br-cAMP (Fig. $6 \mathrm{~B}$, lanes 9-12). These results demonstrated the existence of the RP-2 element- binding factors in the JG cells of the kidney. They also demonstrated that 8-Br-cAMP treatment enhanced renin mRNA expression and the binding of nuclear factors to the RP-2 element in vivo.

\section{Discussion}

The regulation of the renin gene transcription is achieved via the interplay of various signaling stimuli and trans-acting nuclear factors. All of the mouse renin genes (Ren-1C, Ren-1D, and Ren-2 genes) are expressed abundantly and equivalently in the kidney, and 5 '-flanking regions of these genes are highly homologous to $\sim 79$ nucleotides upstream from the transcription start site. We supposed that the highly homologous 5'-flanking regions were involved in the basal transcriptional activity of these renin genes. Thus, in this and previous experiments, we have focused on the promoter region from -365 to +16 of the renin gene (Ren-1C). We previously demonstrated that the Ren-1C promoter region from -365 to +16 could mediate the 293 celldominant transcriptional activity and combination of the RU-1 $(-224$ to -138$)$ and RP-2 $(-75$ to -47$)$ elements efficiently promoted transcription of the Ren-1C promoter (9). In this study, we confirmed that the promoter region from -365 to $+16(\mathrm{mRn} 365 \mathrm{CAT})$ was able to direct the activation of CAT expression by CAMP, and we indicated that the proximal promoter region from -75 to +16 (mRn75CAT) was sufficient to confer this activation property by cAMP. Furthermore, we suggested that the RU-1 element was involved to achieve high level cAMP-induced CAT activation, and that the RP-2 element was essential for cAMP responsiveness.

Second messenger cAMP is a well-characterized regulator of gene expression, including the transcriptional modulation of 
A

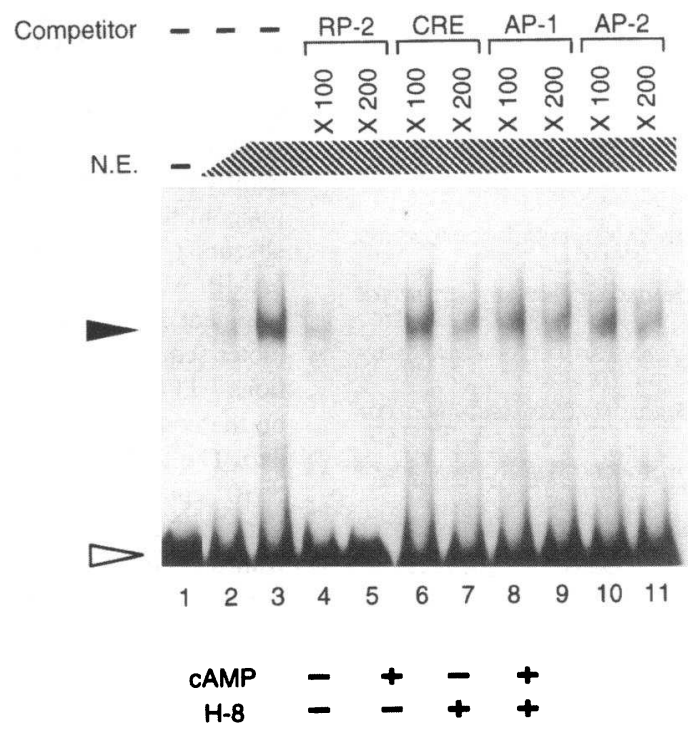

B

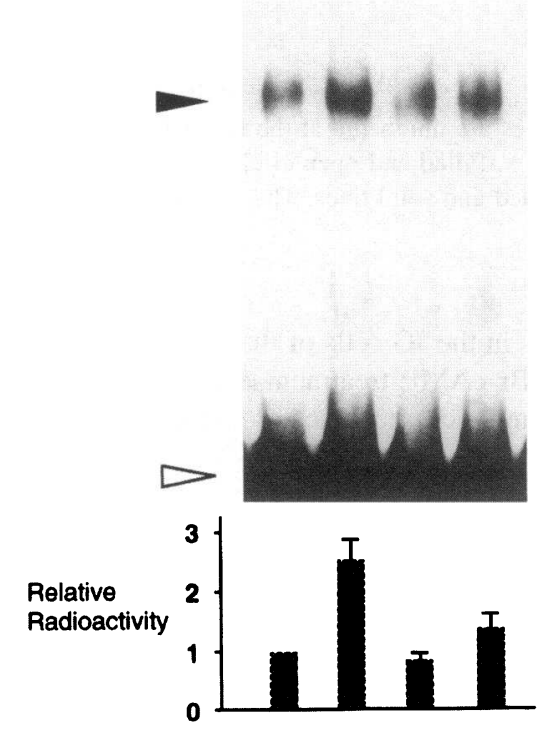

Figure 5. Analysis of nuclear factor binding to the RP-2 element by EMSA. ( $A$ ) EMSA and electrophoretic mobility shift competition assay using the RP-2 element and the consensus oligonucleotides for CREB/ ATF, AP-1, and AP-2. Nuclear extracts from 293 cells (lane 2, $7.5 \mu \mathrm{g}$; lanes $3-11,15 \mu \mathrm{g}$ ) were incubated with the probe. In competition assay, 100 - or 200 -fold molar excess of the competitor DNA was added to the reaction mixture. Lane 1 contains no nuclear extract. The solid and open arrowheads indicate specific DNA-protein complex and free probe, respectively. $(B)$ Effect of cAMP and H-8 on nuclear factor binding to the RP-2 element. 293 cells were incubated in the presence $(+)$ or absence (-) of $1 \mathrm{mM} 8-\mathrm{Br}-\mathrm{cAMP}$ and $15 \mu \mathrm{M} \mathrm{H-8}$ for $36 \mathrm{~h}$. Binding reactions were carried out as in $A$, using $15 \mu \mathrm{g}$ of nuclear extracts. Relative radioactivities of the shifted bands (solid arrowhead) were quantitated using FUJIX BIO-Imaging Analyzer BAS2000 (Fuji Photo Film), and determined by averaging five experiments and comparing them with those obtained from cAMP (-)/H-8 (-) cells.

several hormone and enzyme genes (43). The transcription factor CREB was described as the first CRE-binding protein in eukaryotic cells, and the binding activity of this factor was regulated by cAMP (44-47). The ATF family of transcription factors are structurally related to CREB, and the bindings of these factors are also controlled by CAMP $(48,49)$. In addition, the transcription factors AP-1 and AP-2 have also been implicated in conferring the cAMP-mediated induction of several gene expressions (50-52). Within the renin gene (Ren-1C) promoter from -365 to +16 , there are consensus-like sequences for the transcription factors AP-1 and AP-2, each of which are potential candidates as mediators of cAMP responsiveness (see Fig. $4 \mathrm{~B}$ ). In this study, analysis of $5^{\prime}$-promoter deletion mutants revealed that the RP-2 element from -75 to -47 mediated the cAMP responsiveness. Although this element was clearly necessary for the transcriptional response to cAMP, another upstream element, the RU-1 element from -224 to -138 , was also needed to accomplish the high level promoter activation upon cAMP treatment by proximal promoter.

The functional role of the RU-1 element in cAMP-induced Ren-1C promoter activity was similar to that in the basal transcriptional activity. We showed previously that the RU-1 element efficiently directed transcription of the Ren-1C promoter only in combination with the RP-2 element (9). Our results in this study show that the RU-1 element alone is not able to confer CAMP responsiveness to the Ren-1C and TK promoters, and suggests that the RU-1 element is a constitutive activatorlike region. On the other hand, the RP-2 element seems to be essentially involved in cAMP-mediated induction. We performed DNase I footprint analysis to identify the nature of the DNA-binding activities that occurred at the RP-2 element. We demonstrated that nuclear factors in 293 cell nuclear extracts bound to the region from -68 to -55 in the RP-2 element, overlapping the TATA-like region.

Although the RP-2 element does not contain the putative CRE sites, there is the consensus-like binding motif for AP-2 in the RP-2 element, which may be involved in cAMP response. AP-2 is the transcription factor that mediates induction by two different signal-transduction pathways, protein kinase $A$ and protein kinase $C$ (52). Previous studies have shown that the AP-2-binding sites could form inducible cell type-specific enhancer of many genes (53). Thus, we initially supposed that the AP-2 consensus-like site in the RP- 2 element was involved in cAMP-mediated induction of CAT expression in 293 cells. However, no corresponding footprint was observed using 293 cell nuclear extracts, and the double-stranded oligonucleotides for the consensus-binding site for AP- 2 did not compete for the RP-2 element binding, suggesting that the AP-2 family transcription factors did not participate in cAMP-mediated activation by the RP-2 element.

The activation of gene transcription in response to cAMP usually involves the induction of nuclear binding factor, as observed in the cases of CREB/ATFs and AP-1 (54). Although the results of DNase I footprinting in this study disclosed no significant change in the protected region by cAMP, EMSA showed that the binding activity of nuclear factors to the RP-2 element increased with cAMP treatment. In addition, the results of CAT assay indicated that the RP-2 element was able to confer cAMP inducibility, and that $\mathrm{H}-8$ treatment greatly decreased this cAMP-mediated activation of CAT expression. From the results of CAT assay and EMSA, we suggested that the CAMPprotein kinase pathway might be involved in the nuclear factors binding to the RP-2 element and in the activation process by the RP-2 element-binding factors to promote transcription. Interestingly, electrophoretic mobility shift competition assay indicated that the RP-2-element binding proteins were distinct from AP-1, AP-2, and CREB/ATF family transcription factors, 
A
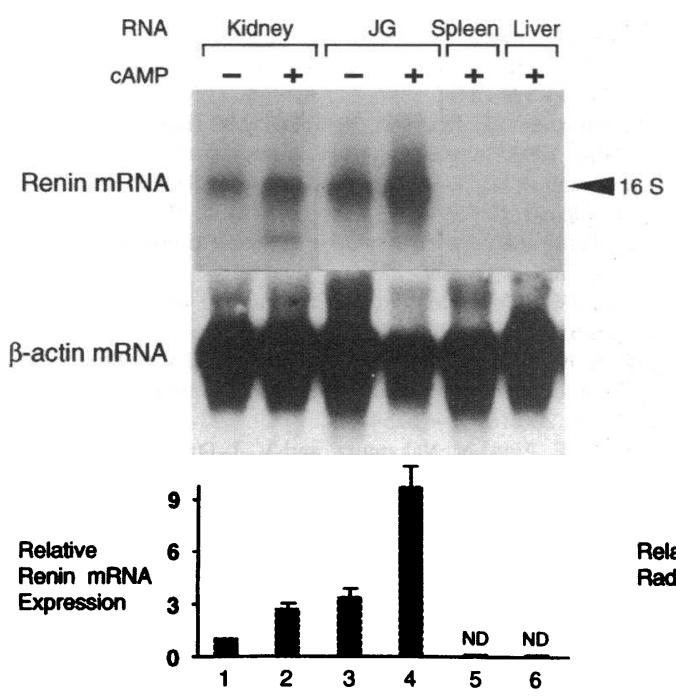

B
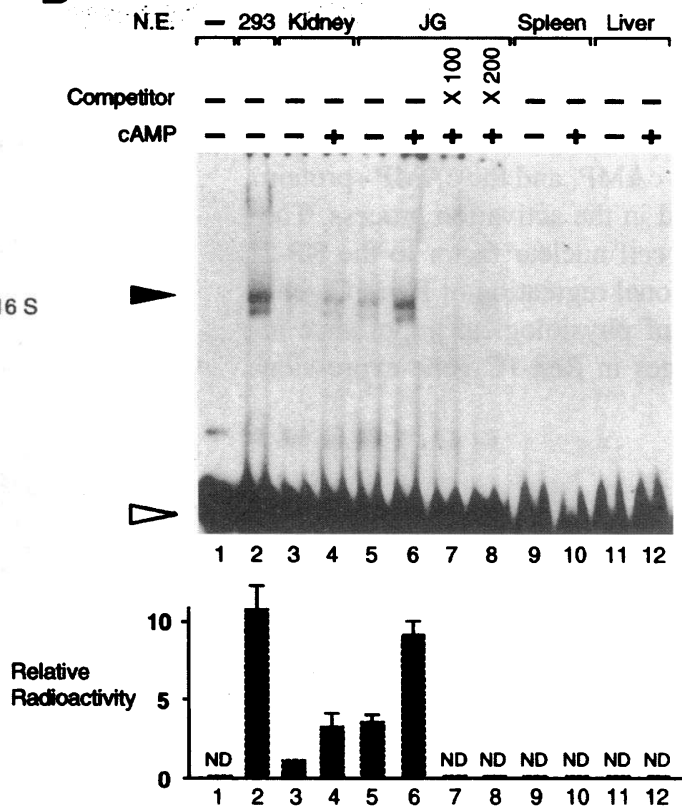

Figure 6. Effect of cAMP on renin mRNA expression and nuclear factor binding to the RP-2 element in vivo. Mice were injected with 8-Br-cAMP ( $10 \mathrm{mg} / \mathrm{kg}$ body wt, i.p.) $(+)$ or an equal volume of vehicle (-) $5 \mathrm{~h}$ before killing. Total RNA and nuclear extracts were prepared from kidney, enriched JG cells, spleen, and liver. $(A)$ Northern blot analysis of renin and $\beta$-actin mRNA expression in the kidney, enriched JG cells, spleen, and liver. Marker for 16S rRNA is indicated by the solid arrowhead. Expression of a constitutive $\beta$-actin mRNA is shown as an internal control. The level of expression of renin mRNA was quantitated using FUJIX BIO-Imaging Analyzer BAS2000 (Fuji Photo Film), compared with that in the kidney of cAMP (-), and nor-

malized to the signal generated by probing for $\beta$-actin gene expression. Values were mean $\pm \operatorname{SEM}(n=3)$. $(B)$ Analysis of nuclear factors binding to the RP-2 element by EMSA in 293 cells (lane 2), kidney (lanes 3 and 4), enriched JG cells (lanes 5-8), spleen (lanes 9 and 10), and liver (lanes 11 and 12). Nuclear extracts (lanes $2-12,5 \mu \mathrm{g}$ ) were incubated with the probe. In competition assay, 100- or 200-fold molar excess of the unlabeled RP-2 element was added to the reaction mixture. Lane $l$ contains no nuclear extract. The solid and open arrowheads indicate specific DNA-protein complex and free probe, respectively. Relative radioactivities of the shifted bands (solid arrowhead) were quantitated using FUJIX BIO-Imaging Analyzer BAS2000 (Fuji Photo Film), and were determined by averaging three experiments and comparing them with those obtained from the kidney of cAMP $(-)$.

which were reported to be induced to bind to their recognition sites. Recently, Horiuchi et al. $(22,23)$ reported that CREB and negative regulatory element (NRE) - binding protein bound to the upstream 5'-flanking region of the mouse renin genes (Ren-1D, -619 to -597 ; Ren-2, -670 to -648 ), and suggested that these nuclear proteins played a role in the regulation of renin gene transcription. However, they performed transient transfection assay using a heterologous TK promoter instead of the native renin core promoter sequences, and the functional importance of the proximal promoter sequences in cAMP-mediated activation was not examined. On the other hand, Duncan et al. showed that the proximal 100 -bp segment, a region of high interspecies homology, was able to direct accurate tissuespecific initiation of transcription and mediate cAMP-induced activation of CAT expression, using primary cultures of placental cells. Although we do not know the exact nucleotide sequences of the far upstream 5'-flanking region beyond -365 of the Ren-1C gene, it is probable that the Ren-1C gene has the upstream CRE and NRE sites, as the Ren-1D and Ren-2 genes have. Concerning the RP-2 element, the sequences of the mouse (Ren-1C, Ren-1D, and Ren-2), rat, and human renin genes are highly homologous, and the RP-2 element seems to be functional in these renin genes. In this transfection study, the CRE and RP-2 element additively increased the cAMPmediated CAT expression directed by the Ren-1C and TK promoters (Fig. 2). Therefore, it is possible that both the upstream CRE and proximal RP-2 element are involved in the cAMPmediated activation of the renin genes promoter. Further study, including the molecular cloning, is needed to analyze the molecular relationship between the RP-2 element and the upstream
CRE site, and to determine whether the RP-2-binding protein is a novel transcriptional modulator of the renin gene.

Renin is mainly produced in JG cells of the kidney. To further investigate whether the RP-2 element is relevant to the regulation of the Ren-1C promoter in vivo, we performed Northern blot analysis and EMSA using total RNA and nuclear extracts prepared from enriched JG cells of the kidney, respectively. The JG cells were major expression sites of renin in the kidney, and cAMP treatment resulted in an elevation of renin mRNA level in the kidney and enriched JG cells, as reported in previous and recent studies $(1,2,55-57)$. It was noted that cAMP treatment enhanced the binding of nuclear factors to the RP-2 element in vivo. We previously showed that the human renin gene promoter was specifically activated in JG cells of the kidney using the transgenic mouse model $(8,33)$. EMSA using kidney and JG cell nuclear extracts revealed the tissueand cell-specific presence of a DNA-protein interaction at the RP-2 element (Fig. 6), and showed that the binding activity increased by cAMP in the JG cells of the kidney. These results suggested that the nuclear factors binding to the RP-2 element were regulated by cAMP in the tissue- and cell-specific manner, and that the RP-2 element was involved in regulating the Ren1C gene transcription in vivo. Recent studies using primary cultured JG cells reported that the increase in mRNA stability might take part in cAMP-induced activation of the renin gene expression $(56,57)$, and further study would be necessary to clarify the functional role of mRNA stability in the regulation of renin gene expression by cAMP.

The data we present in this study demonstrate that cAMP activates the Ren-1C gene proximal promoter in kidney-derived 
cells, and that this effect is mediated mainly via a proximal promoter element from -75 to -47 (RP-2 element), overlapping the TATA-like region. Transcription factors distinct from AP-1, AP-2, or ATF/CREB family appear to be mediators of this cAMP response, and nuclear factors binding to the RP-2 element seem to be regulated by cAMP, and the CAMP-protein kinase pathway may be involved in the activation process. The cAMP-regulated binding of JG cell nuclear factor to the RP-2 element suggests that transcriptional regulation of Ren-1C gene by proximal promoter may be of physiological importance in mediating cAMP-induced changes in Ren-1C gene expression in vivo.

\section{Acknowledgments}

We thank Dr. Katsuo Tokunaga (Chiba Cancer Center Research Institute, Chiba-ken, Japan) for the generous gift of the mouse skeletal $\beta$ actin cDNA probe. We would like to express our thanks to Dr. Keiji Tanimoto (Institute of Applied Biochemistry, University of Tsukuba) for helpful discussion. We also thank Chiaki Hayashi and Toshiko Shibuya for technical assistance.

This study was supported in part by grants-in-aid for Scientific Research $(05454275,0104412,02670404$, and 4512) from the Ministry of Education, Science, and Culture of Japan. Dr. Kouichi Tamura is supported by a Research Fellowship of the Japan Society for the Promotion of Science for Young Scientists.

\section{References}

1. Griendling, K. K., T. J. Murphy, and R. W. Alexander. 1993. Molecular biology of the renin-angiotensin system. Circulation. 87:1816-1828.

2. Dzau, V. J., D. W. Burt, and R. E. Pratt. 1988. Molecular biology of the renin-angiotensin system. Am. J. Physiol. 255:F563-F573.

3. Mullins, J. J., J. Peters, and D. Ganten. 1990. Fulminant hypertension in transgenic rats harbouring the mouse Ren-2 gene. Nature (Lond.). 344:541-544.

4. Laragh, J. H. 1992. The renin system and four lines of hypertension research nephron heterogeneity, the calcium connection, the prorenin vasodilator limb, and plasma renin and heart attack. Hypertension (Dallas). 20:267-279.

5. Ganten, D., J. Wagner, K. Zeh, M. Bader, J. B. Michel, M. Paul, F Zimmermann, P. Ruf, U. Hilgenfeldt, U. Ganten, et al. 1992. Species specificity of renin kinetics in transgenic rats harboring the human renin and angiotensinogen genes. Proc. Natl. Acad. Sci. USA. 89:7806-7810.

6. Tomita, N., J. Higaki, Y. Kaneda, H. Yu, R. Morishita, H. Mikami, and T. Ogihara. 1993. Hypertensive rats produced by in vivo introduction of the human renin gene. Circ. Res. 73:898-905.

7. Fukamizu, A., M. S. Seo, T. Hatae, M. Yokoyama, T. Nomura, M. Katsuki, and K. Murakami. 1989. Tissue-specific expression of the human renin gene in transgenic mice. Biochem. Biophys. Res. Commun. 165:826-832.

8. Fukamizu, A., T. Hatae, Y. Kon, M. Sugimura, T. Hasegawa, M. Yokoyama, T. Nomura, M. Katsuki, and K. Murakami. 1991. Human renin in transgenic mouse kidney is localized to juxtaglomerular cells. Biochem. J. 278:601-603.

9. Tamura, K., K. Tanimoto, K. Murakami, and A. Fukamizu. 1992. A combination of upstream and proximal elements is required for efficient expression of the mouse renin promoter in cultured cells. Nucleic Acids Res. 20:3617-3623.

10. Tamura, K., K. Tanimoto, K. Murakami, and A. Fukamizu. 1993. Activation of mouse renin promoter by cAMP and c-Jun in a kidney-derived cell line. Biochim. Biophys. Acta. 1172:306-310.

11. Sun, J., C. Oddoux, A. Lazarus, M. T. Gilbert, and D. F. Catanzaro. 1993 Promoter activity of human renin 5'-flanking DNA sequences is activated by the pituitary-specific transcription factor Pit-1. J. Biol. Chem. 268:1505-1508.

12. Jones, C. A., C. D. Sigmund, R. A. McGowan, C. M. Kane-Haas, and K. W. Gross. 1990. Temporal and spatial expression of the murine renin genes during fetal development. Mol. Endocrinol. 4:375-383.

13. Sigmund, C. D., C. A. Jones, J. R. Fabian, J. J. Mullins, and K. W. Gross. 1990. Tissue- and cell-specific expression of a renin promoter- $T$ antigen reporter gene construct in transgenic mice. Biochem. Biophys. Res. Commun. 170:344350 .

14. Sigmund, C. D., and K. W. Gross. 1991. Structure, expression, and regulation of the murine renin genes. Hypertension (Dallas). 18:446-457.

15. Burt, D. W., N. Nakamura, P. Kelley, and V. J. Dzau. 1989. Identification of negative and positive regulatory elements in the human renin gene. J. Biol. Chem. 264:7357-7362.

16. Ballermann, B. J., M. L. Zeidel, M. E. Gunning, and B. M. Brenner. 1991.
Vasoactive peptides and the kidney. In The Kidney. B. M. Brenner and F. C. Rector, Jr., editors. W. B. Saunders Company, Philadelphia. pp. 510-583.

17. Umemura, S., D. D. Smyth, and W. A. Pettinger. 1986. Regulation of renal cellular cAMP levels by prostaglandins and $\alpha_{2}$-adrenoceptors: microdissection studies. Kidney Int. 29:703-707.

18. Umemura, S., Y. Toya, N. Hirawa, Y. Ishikawa, K. Minamisawa, G. Yasuda, S. Hayashi, and M. Ishii. 1989. Inhibitory effect of human atrial natriuretic peptide on cyclic AMP levels in microdissected human glomeruli. $J$. Cardiovasc. Pharmacol. 13:S36-S38.

19. Toya, Y., S. Umemura, T. Iwamoto, K. Takeda, N. Hirawa, M. Kihara, N. Takagi, and M. Ishii. 1993. Identification and characterization of adenosine A1 receptor-cAMP system in human glomeruli. Kidney Int. 43:928-932.

20. Everett, A. D., R. M. Carey, R. L. Chevalier, M. J. Peach, and R. A. Gomez. 1990. Renin release and gene expression in intact rat kidney microvessels and single cells. J. Clin. Invest. 86:169-175.

21. Rayson, B. M. 1992. Juxtaglomerular cells cultured on a reconstituted basement membrane. Am. J. Physiol. 262:C563-C568.

22. Horiuchi, M., N. Nakamura, S.-S. Tang, G. Barrett, and V. J. Dzau. 1991. Molecular mechanism of tissue-specific regulation of mouse renin gene expression by cAMP. J. Biol. Chem. 266:16247-16254.

23. Horiuchi, M., R. E. Pratt, N. Nakamura, and V. J. Dzau. 1993. Distinct nuclear proteins competing for an overlapping sequence of cyclic adenosine monophosphate and negative regulatory elements regulate tissue-specific mouse renin gene expression. J. Clin. Invest. 92:1805-1811.

24. Duncan, K. G., M. A. Haidar, J. D. Baxter, and T. L. Reudelhuber. 1990. Regulation of human renin expression in chorion cell primary cultures. Proc. Natl. Acad. Sci. USA. 87:7588-7592.

25. Tanimoto, K., K. Murakami, and A. Fukamizu. 1993. Possible roles of the 3 '-flanking sequences of the human activin $\beta \mathrm{A}$ subunit gene in its expression. Arch. Biochem. Biophys. 302:409-416.

26. Deutsch, P. J., J. L. Jameson, and J. F. Habener. 1987. Cyclic AMP responsiveness of human gonadotropin-a gene transcription is directed by a repeated 18-base pair enhancer: a promoter receptivity to the enhancer confers cellpreferential expression. J. Biol. Chem. 262:12169-12174.

27. Fukamizu, A., S. Takahashi, M. S. Seo, M. Tada, K. Tanimoto, S. Uehara, and K. Murakami. 1990. Structure and expression of the human angiotensinogen gene: identification of a unique and highly active promoter. J. Biol. Chem. 265:7576-7582.

28. Hidaka, H., M. Inagaki, S. Kawamato, and Y. Sasaki. 1984. Isoquinolinesulfonamides, novel and potent inhibitors of cyclic nucleotide dependent protein kinase and protein kinase C. Biochemistry 23:5036-5041.

29. Tamura, K., K. Tanimoto, S. Takahashi, M. Sagara, A. Fukamizu, and K. Murakami. 1992. Structure and expression of the mouse angiotensinogen gene. Jpn. Heart J. 33:113-124.

30. Tamura, K., K. Tanimoto, M. Ishii, K. Murakami, and A. Fukamizu. 1993. Proximal and core DNA elements are required for efficient angiotensinogen promoter activation during adipogenic differentiation. J. Biol. Chem. 268:1502415032.

31. Tamura, K., S. Umemura, T. Iwamoto, S. Yamaguchi, S. Kobayashi, K. Takeda, Y. Tokita, N. Takagi, K. Murakami, A. Fukamizu, and M. Ishii. 1994 Molecular mechanism of adipogenic activation of the angiotensinogen gene. $H y$ pertension (Dallas). 23:364-368.

32. Chomczynski, P., and N. Sacchi. 1987. Single-step method of RNA isolation by acid guanidinium thiocyanate-phenol-chloroform extraction. Anal. Biochem. 162:156-159.

33. Fukamizu, A., S. Uehara, K. Sugimura, Y. Kon, M. Sugimura, T. Hasegawa, M. Yokoyama, T. Nomura, M. Katsuki, and K. Murakami. 1991. Cell typespecific expression of the human renin gene. J. Biol. Regul. Homeostatic Agents. 5:112-116.

34. Tokunaga, K., H. Taniguchi, K. Yoda, M. Shimizu, and S. Sakiyama. 1986. Nucleotide sequence of a full-length cDNA for mouse cytoskeletal $\beta$-actin mRNA. Nucleic Acids Res. 14:2829.

35. Dignam, J. D., R. M. Lebovitz, and R. G. Roeder. 1983. Accurate transcription initiation by RMA polymerase II in a soluble extract from isolated mammalian nuclei. Nucleic Acids Res. 11:1475-1489.

36. Swick, A. G., M. C. Blake, J. W. Kahn, and J. C. Azizkhan. 1989. Functional analysis of GC element binding and transcription in the hamster dihydrofolate reductase gene promoter. Nucleic Acids Res. 17:9291-9304.

37. Gorski, K., M. Carneiro, and U. Schibler. 1986. Tissue-specific in vitro transcription from the mouse albumin promoter. Cell. 47:767-776.

38. Kurtz, A., R. D. Bruna, J. Pfeilschifter, R. Taugner, and C. Bauer. 1986. Atrial natriuretic peptide inhibits renin release from juxtaglomerular cells by a cGMP-mediated process. Proc. Natl. Acad. Sci. USA. 83:4769-4773.

39. Tamura, K., S. Umemura, M. Ishii, K. Tanimoto, K. Murakami, and A. Fukamizu. 1994. Molecular mechanism of transcriptional activation of angiotensinogen gene by proximal promoter. J. Clin. Invest. 93:1370-1379.

40. Maxam, A. M., and W. Gilbert. 1980. Sequencing end-labeled DNA with base-specific chemical cleavages. Methods Enzymol. 65:499-560.

41. Fukamizu, A., K. Tanimoto, S. Uehara, M. S. Seo, S. Handa, M. Sagara, S. Takahashi, T. Imai, and K. Murakami. 1991. Regulation of human renin and angiotensinogen genes. Biomed. Biochim. Acta. 50:659-663. 
42. Morris, B. J. 1992. Molecular biology of renin II: gene control by messenger RNA, transfection, and transgenic studies. J. Hypertens. 10:337-342.

43. Roesler, W. J., G. R. Vandenbark, and R. W. Hanson. 1988. Cyclic AMP and the induction of eukaryotic gene transcription. J. Biol. Chem. 263:90639066.

44. Montminy, M. R., K. A. Sevarino, J. A. Wagner, G. Mandel, and R. H Goodman. 1986. Identification of a cyclic-AMP-responsive element within the rat somatostatin gene. Proc. Natl. Acad. Sci. USA. 83:6682-6686.

45. Montminy, M. R., and L. M. Bilezikjian. 1987. Binding of a nuclear protein to the cyclic-AMP response element of the somatostatin gene. Nature (Lond.). 328:175-178.

46. Foulkes, N. S., E. Borrelli, and P. Sassone-Corsi. 1991. CREM gene: use of alternative DNA-binding domains generates multiple antagonists of cAMPinduced transcription. Cell. 64:739-749.

47. Quinn, P. G. 1993. Distinct activation domains within cAMP response element-binding protein (CREB) mediate basal and cAMP-stimulated transcription. J. Biol. Chem. 268:16999-17009.

48. Lin, Y. S., and M. R. Green. 1988. Interaction of a common cellular transcription factor, ATF, with regulatory elements in both Ela- and cyclic AMPinducible promoters. Proc. Natl. Acad. Sci. USA. 85:3396-3400.

49. Rehfuss, R. P., K. M. Walton, M. M. Loriaux, and R. H. Goodman. 1991. The cAMP-regulated enhancer-binding protein ATF-1 activates transcription in response to cAMP-dependent protein kinase A. J. Biol. Chem. 266:18431-18434.

50. Hai, T., and T. Curran. 1991. Cross-family dimerization of transcription factors Fos/Jun and ATF/CREB alters DNA binding specificity. Proc. Natl. Acad. Sci. USA. 88:3720-3724

51. Sassone-Corsi, P. L. J. Ransone, and I. M. Verma 1990. Cross-talk in signal transductions: TPA-inducible factor jun/AP-1 activates cAMP-responsive enhancer elements. Oncogene. 5:427-431.

52. Imagawa, M., R. Chiu, and M. Karin. 1987. Transcription factor AP-2 mediates induction by two different signal-transduction pathways: protein kinase $\mathrm{C}$ and cAMP. Cell. 51:251-260.

53. Williams, T., and R. Tjian. 1991. Analysis of the DNA-binding and activation properties of the human transcription factor AP-2. Genes \& Dev. 5:670682.

54. Pardy, K., R. A. H. Adan, D. A. Carter, V. Seah, J. P. H. Burbach, and D. Murphy. 1992. The identification of a cis-acting element involved in cyclic 3', $5^{\prime}$-adenosine monophosphate regulation of bovine vasopressin gene expression. $J$. Biol. Chem. 267:21746-21752.

55. Paul, M., D. W. Burt, J. E. Krieger, N. Nakamura, and V. J. Dzau. 1992. Tissue specificity of renin promoter activity and regulation in mice. Am. J. Physiol. 262:E644-E650

56. Bruna, R. D., A. Kurtz, P. Corvol, and F. Pinet. 1993. Renin mRNA quantification using polymerase chain reaction in cultured juxtaglomerular cells. Circ. Res. 73:639-648.

57. Chen, M., J. Schnermann, A. M. Smart, F. C. Brosius, P. D. Killen, and J. P. Briggs. 1993. Cyclic AMP selectively increases renin mRNA stability in cultured juxtaglomerular granular cells. J. Biol. Chem. 268:24138-24144. 